\title{
Contested Objects: Curating Soldier Art
}

\author{
Holly Furneaux*, Sue Prichard**
}

\begin{abstract}
'all of six years on and off to make the quilt from different uniforms, more than a few pieces from poor fellows that fought hard for their country and fell in the struggle.'

Joseph Rawdon, British soldier in India, 1872 Letter to Mr Bootland of Bradford, quoted by Rae and Tucker 1995: 177.
\end{abstract}

\begin{abstract}
Joseph Rawdon's account of his making of a military quilt incorporates an emotional object biography of a kind typically attached to this kind of material. He recalls the long period of production, an investment of physical and emotional labour of a different, but related, order to the effort of his dead colleagues, those 'poor fellows that fought hard for their country and fell in the struggle', and whose then surplus uniforms contribute to the fabric of the patchwork. In this co-authored article we draw upon objects like that produced by Rawdon, and the narratives that accompany them, to explore the value and challenges of curating objects produced by soldiers in wartime. Focusing on patchwork produced by Victorian military men, we seek to extend the understanding of trench art, in terms of chronology and form.
\end{abstract}

Existing work on trench art has been almost exclusively directed to the First World War, with a particular emphasis on objects made from weaponry and ammunition, such as shell casing vases. Nicholas Saunders, the leading scholar in this field, gives the following definition: 'Any object made by soldiers, prisoners of war and civilians, from war material or any other material as long as object and maker are associated in time and space with armed conflict or its consequences' (2002: 4). Jane Kimball, whose work also concentrates on the First World War, uses similar criteria, looking at how soldiers and civilians 'transformed materials designed to kill other human beings into an amazing creative and diverse body of folk art that has been largely ignored [. . .] until recently' (2004: xi). In looking at Victorian soldiers' remaking of military uniforms in patchwork, we take up the expansive potential of these definitions to think about forms of tactile experience in wartime that extend beyond the cleaning, loading, firing and craft-working of weaponry.

A different experience of touch and emotion is involved in the production and later curation of nineteenth-century military textiles, and in what follows we pay particular attention to the personal histories attached to these kinds of objects, including the recurring narrative of quilts having been pieced from the uniforms of dead comrades. As we will argue, the production of crafted objects from textiles, often recycled, is strongly connected with the virtues of gainful employment, skills based learning and exhibition culture. ${ }^{2}$

The materials considered here raise questions about the emotional effects of producing, gathering, gifting and using such items for soldiers and civilians whereby 'cloth persists as a medium of personal meaning-making and cultural memory' (Jacob 2007: 299-300), and about the politics and affects of the reuse of war materials. Our readings of these objects and the narratives attached to them is informed, variously, by work on gender, handicraft and touch, scholarship on memory, materiality and mourning, and theories of resonant or numinous objects. ${ }^{3}$ Whilst collections and exhibitions place understandable emphasis on provenance, 
we also want to explore the significance of the handed-on stories, or object biographies, that become interwoven with these things. ${ }^{4}$ We suggest that such objects can be used to rethink the gendering of craftwork in the nineteenth century, and to recover untold stories of military experience, emphasizing soldiers' tactile and emotional engagements, and exploring shared threads of feeling between home, battlefield, and hospital.

\section{Curating a Military Quilt: 'Quilts 1700-2010'}

In 2010 the Victoria \& Albert Museum displayed an excellent example of a nineteenth-century military quilt in the 'Quilts 1700-2010' exhibition (V\&A 20 March - 1 July 2010). Intensive research suggests that 'The Brayley Quilt', as it became known, was owned and probably produced by Private Francis Brayley while he was stationed in India in the 1860s and 70s.

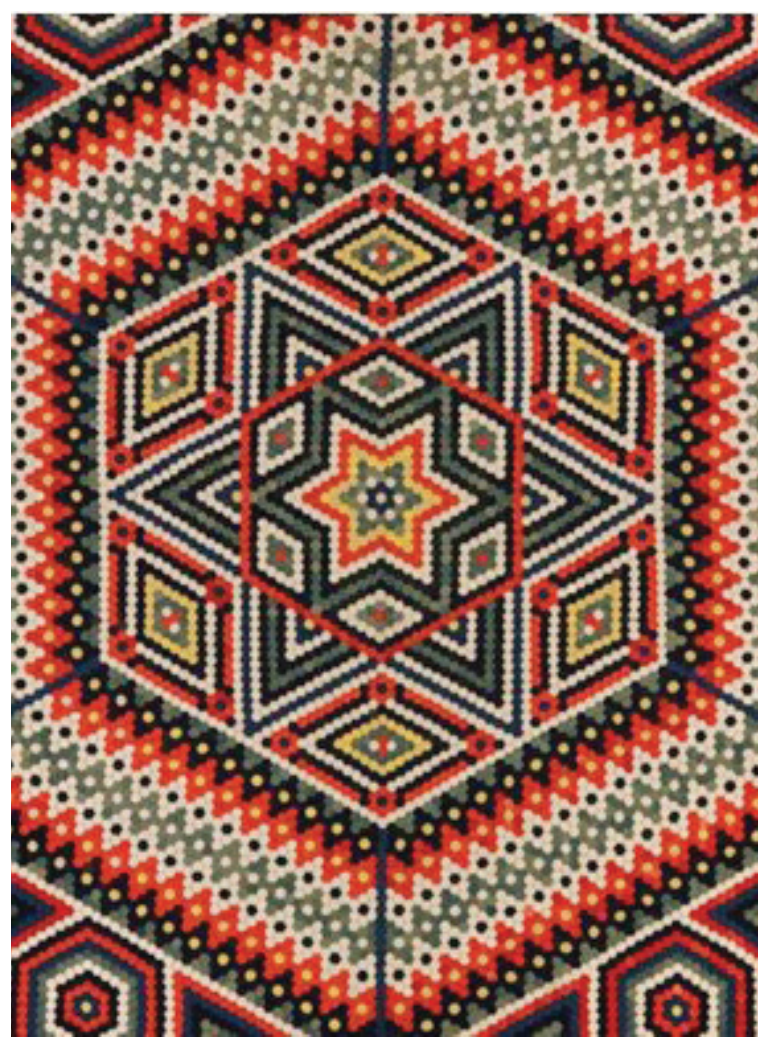

Fig 1. 'The Brayley Quilt', Military patchwork quilt, possibly Private Francis Brayley, India, 1864-1877 (T.58-2007) Reproduced with permission from Victoria and Albert Museum. light on the history of the alleged maker and in more general terms conditions under which the quilt might have been made (Prichard 2010).

Arranged around a loose chronology, 'Quilts 1700-2010' was unusual in embedding contemporary work with historic - inviting the viewer to create links between the past and present and offering an emotional connection between the experiences of the makers. Within literature and the visual arts, patchwork and quilt making are inextricably linked with 'women's work'. This notion was reinforced by some of the reviews of the exhibition, including Philip Hensher's piece for The Mail on Sunday: 
The argument of this exhibition, and of a surprising amount of scholarly work in recent years, is that women, barred from the higher and more dignified forms of art, found themselves expressing their stories and their lives through a domestic craft (2010: 25).

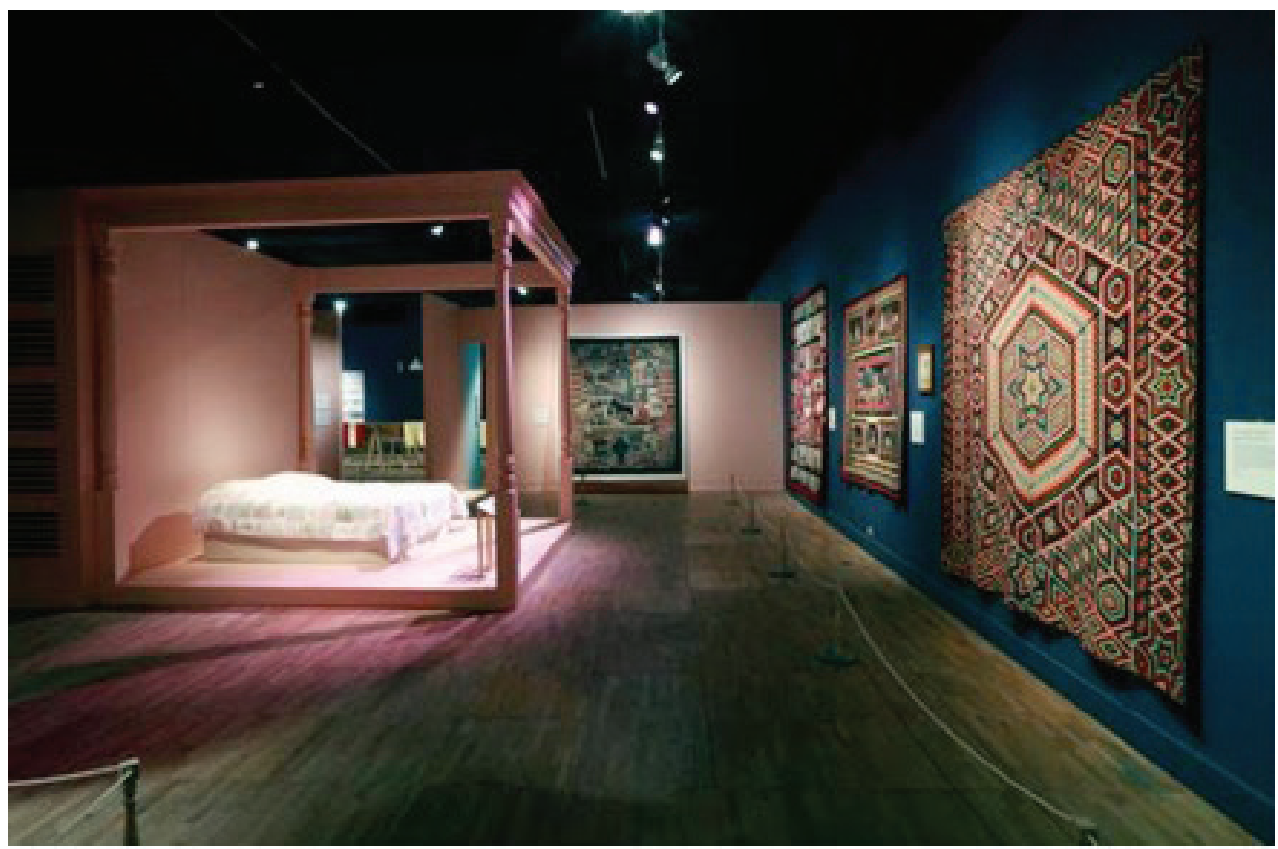

Fig 2. Quilts 1700-2010: Hidden Histories, Untold Stories, Victoria \& Albert Museum, 20 March-04 July 2010, section three, 'Virtue and Virtuosity'Reproduced with permission from Victoria and Albert Museum.

Hensher gestures towards work like Rozsika Parker's seminal publication on the subject of women and embroidery, first published in 1984 and reissued with a new introduction in 2010, and Constance Classen's account of handiwork as a feminine 'aesthetic tactic', 'one which valued touch as well as sight, and communal production as much as individual ability' (Parker 1984; Classen 2005: 205). The exhibition, however, sought to extend such work and complicate the gendered understanding of 'domestic craft' by considering the aesthetic tactics of intricate patchworks produced by both women and men. Exhibited in the thematic section entitled 'Virtue and Virtuosity', the Brayley military quilt was juxtaposed with pictorial inlaid patchwork (intarsia) hangings made by tailors specifically for exhibition and education purposes. Although not specifically connected with military service, John Munro's 'Royal Clothograph' (c.1830-50) and a later example, Menzie Moffatt's 'The Royal Crimean Hero Tablecover' (1865-1880), share characteristics associated with military quilts, in the piecing of geometric shapes mostly employed as decorative devices framing individual scenes or portraits. Materials and techniques used in the production of tailors' quilts or hangings differ from that of traditional domestic patchwork: 'intarsia' or 'inlaid patchwork' is similar to the woodwork method of marquetry whilst fuelled wool, also known as felted tailors' broadcloth, was best suited to the highly skilled over-sewing involved in piecing the sometimes minute pieces of fabric together.

Textile historian Clare Rose (2009) has written extensively on inlaid patchwork and British exhibition culture noting that four examples of inlaid patchwork were displayed at the Great Exhibition (1851), as well as at national and local exhibitions. The publicity generated by such displays of skill and virtuosity firmly link these objects with the nineteenth century Temperance Movement and campaigns against the 'evils of drink'. John Munro (1811-1888), 
a master tailor based in Glasgow exhibited 'The Royal Clothograph Work of Art', a large seven paneled pictorial hanging or table cover at a Belfast Temperance meeting in 1860. Munro's work was evangelically reviewed in the Belfast Newsletter. '[he] illustrated therefrom what patience and perseverance could accomplish, and urged upon the young men present to practise those virtues, and in order to do so, they should become total abstainers' (15 November 1860).

The review from the Belfast Newsletter provides a context in which to read military quilts and challenge prevailing mythology around their production. Joseph Rawdon, quoted at the beginning of this article, declares that the making of his quilt was both time consuming and also an act of loyalty and memorial. His assertion also serves to deflect attention away from more uncomfortable accounts of the scavenging and looting of battlefield souvenirs by both victors and vanquished. ${ }^{6}$ Rawdon imbues his own patchwork with a more acceptable salvage narrative, giving it the status of patriotic relic and 'object of emotion'. This kind of object biography helps to ensure that military quilts are handed down within families as symbols of adventure, duty and, in some cases, sacrifice.

Despite Rawdon's testimony, in reality it is most likely that many military quilts were produced under the auspices of government led agencies. Needlework, in particular embroidery, was encouraged by the Temperance Association, especially in India where the extreme heat was almost unbearable. The use of craftwork for therapeutic purposes was institutionally established by the First World War, and Jeffrey Reznick has done detailed work on the curative workshops in that period, which were 'designed to create an atmosphere of contentment among the men', although, there is evidence that this had mixed success with soldier patients often resenting such work $(2004: 124,128)$. During WWII patchwork was included in the occupational parcels of different kinds of handiwork sent by the War Office to British POWs in overseas prison camps. Thomas Wood's 'Portrait of Private Walker' producing patchwork while convalescing in a military hospital after being invalided from the Crimean war (which will be discussed fully later in this article) may suggest that craftwork was supported as a form of occupational therapy as early as the 1850s.

Patchwork was also a useful tool in teaching sewing skills as recognized by the prison reformer Elizabeth Fry. ${ }^{7}$ The British War Office acknowledged the need for military personnel to learn new skills, urging the establishment of professional workshops supervised by "competent tradesmen', including tailors. There is no evidence in Parliamentary papers to suggest that patchwork was employed as a simple introduction to skills-based learning in regimental workshops. ${ }^{8}$ However, the success of a number of military exhibitions showcasing craft-work during the latter half of the nineteenth century, together with documentary evidence relating to quilt production suggest that patchwork was indeed integrated into camp life.

Contrary to popular belief, most surviving quilts are unsigned or dated, with virtually no documentation to support assertions that they were made by family members. The strong military connections of the Brayley quilt provided opportunities for collaboration across disciplines which helped shed light on the context and production of the quilt. Family members, local historians, the military historian Richard Holmes and retired surgeon and Napoleonic war expert Michael Crumplin contributed to the narrative of one man's experience of serving in India. Research at the National Archives confirmed that one Private Francis Brayley served in the $1^{\text {st }}, 11^{\text {th }}$ Foot (The Devonshire Regiment) and was stationed in India (1864-77). To relieve the boredom of his posting, Private Brayley may have embarked on his patchwork quilt as a hobby, facilitated by a supply of fabric from the offcuts of the regimental tailor. The uniform size of the fabric hexagons, measuring $1.5 \mathrm{cms}$ suggest the pieces were 'punched', possibly using a leather or fabric tool. An examination of the back of the quilt reveals that, despite the complexity of the design, the stitching is extremely rudimentary, consisting of a basic whip or over stitch using a thick thread or several strands of twisted hemp. Although neither Brayley nor the quilt is mentioned in relation to the 1868 and 1869 'Soldiers' Industrial Exhibitions' in Lucknow, the Battalion's entries were considered worthy of commendation by the Commanderin-Chief (Aggett 1994: 146). The Battalion appeared to be more skillful in the sporting arena, coming second in 1868 in an All India League based on the annual musketry course for British Regiments. It is possible that Brayley too may have employed his skills in winning a cash prize, acquiring the quilt as a tangible souvenir of his prowess with the rifle. An examination of the Company's Muster Rolls, reveals that Brayley appears to have enjoyed good health 
until the latter half of 1875 and most of 1876, when he was granted a period of absence for debilitation described as 'Rifle Drill Fatigue', a possible precursor to the onset of tuberculosis. Confined to his bed, Brayley may have used his time productively, convalescing in a similar way to Private Thomas Walker.

Private Francis Brayley returned to England with the 1 st $/ 11^{\text {th }}$ Foot in April 1877. A search of the parish register revealed that Francis Brayley married one Mary Ann Ash, spinster of the parish, one month after arriving back in England. Was the quilt a wedding present for the woman who had waited patiently for thirteen years for the return of her husband to be? Did Brayley consider the quilt a suitable gift for his betrothed? Their marriage certificate states that Mary Ann was a seamstress, and it is possible that she admired both the skill of the maker and the sentiment behind the gift. Less than three years later, Brayley was buried in the village of Mariansleigh, the cause of death described as 'Phthisis', commonly known as tuberculosis or pulmonary consumption. Brayley's occupation at the time of his death was 'pensioner' suggesting that he did not take up the trade of tailor - however he did leave his widow and young son with a souvenir of his military service in India. Exhibitions such as 'Quilts 1700-2010' and 'Homefront \& Battlefield: Quilts \& Context in the Civil War', a pioneering 2012 exhibition which sought to explore the history of this conflict through textiles, reveal a new dimension to quilt production in the nineteenth century and new perspectives on individual experiences.

\section{Military Patchwork and Object Histories}

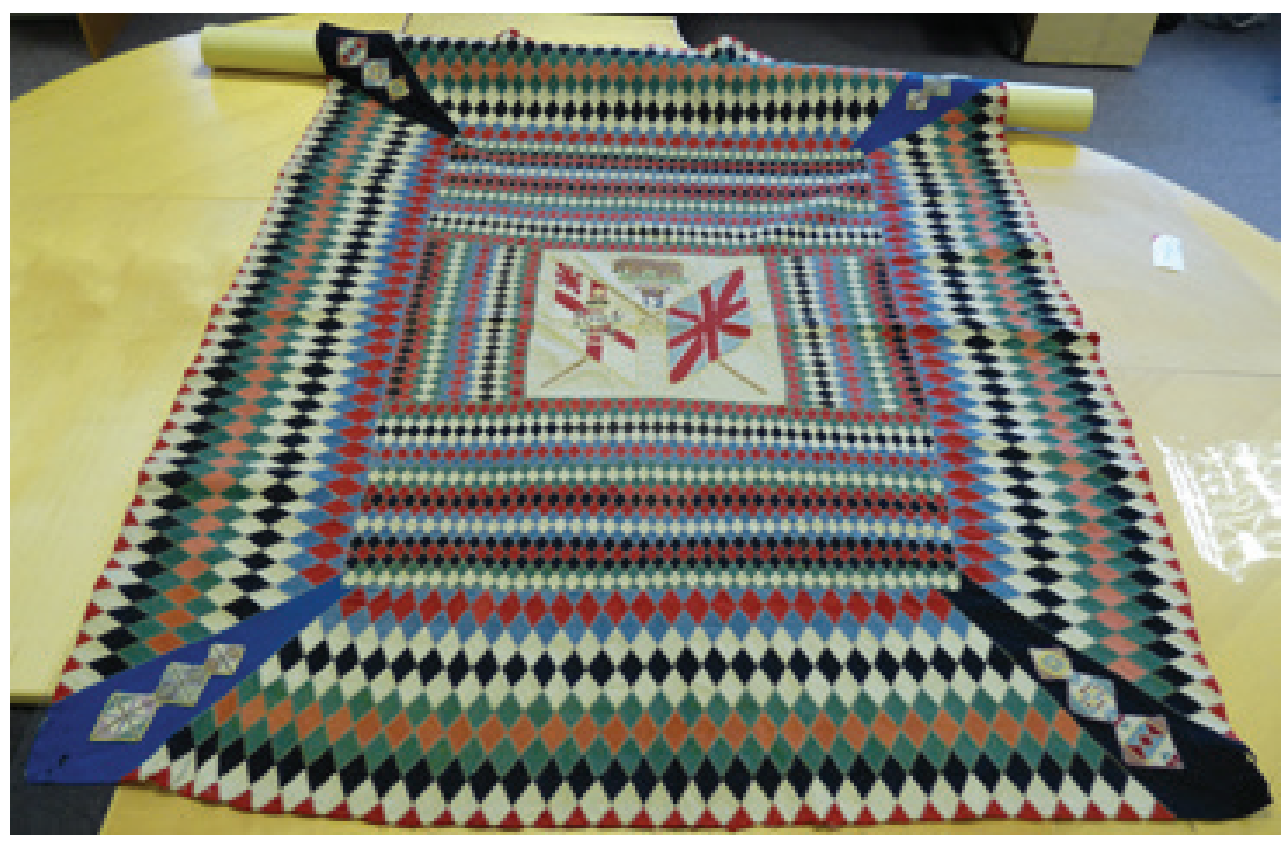

Fig 3. Patchwork Bedcover, 17th Regiment of Foot, c. 1856 (NAM 1992-07-206-1) Reproduced with permission from the National Army Museum

The National Army Museum (NAM) also has some wonderful holdings of soldier-made quilts and other patchwork objects including a patchwork and embroidered bed cover of the 17th (The Leicestershire) Regiment of Foot c1856 (NAM 1992-07-206-1), a fragment of a patchwork coverlet or counterpane made by an unknown British soldier, reputedly in India c1880 (NAM 1981-12-34-1), and two intricate embroidered patchwork smoking caps worked by Colour Sergeant Joseph Fish of the Grenadier Guards during the Crimean War 1854-6 (NAM 196308-185-2 and -3). The 17th Regiment bedcover has a note attached: 'This coverlet was made 
by a soldier recovering from wounds during the Crimean War'. Though no further information is supplied which might help to verify this object biography, this note places the coverlet in a tradition of therapeutic patchwork and could help to support the case for a longer history of institutional support for sewing as part of invalided soldiers' recuperation. The central panel design of the Regimental colour, Queen's colour and Leicester Tiger (the Regimental badge) incorporates some pieces of embroidered appliqué produced on pre-perforated canvas for easier stitching. While in scale and design the work is ambitious, measuring 140 by $162 \mathrm{~cm}$ and using tessellation of two sizes of diamonds of six colours of uniform fabric around the central panel, it has clearly been executed by an amateur. Stitching in the patchwork varies in size and method, and the embroidery technique is improvised. The finished coverlet movingly inscribes the effort of its production, which combines with the attached note to invite those viewing it now to imagine the painstaking work of the unnamed wounded infantryman.

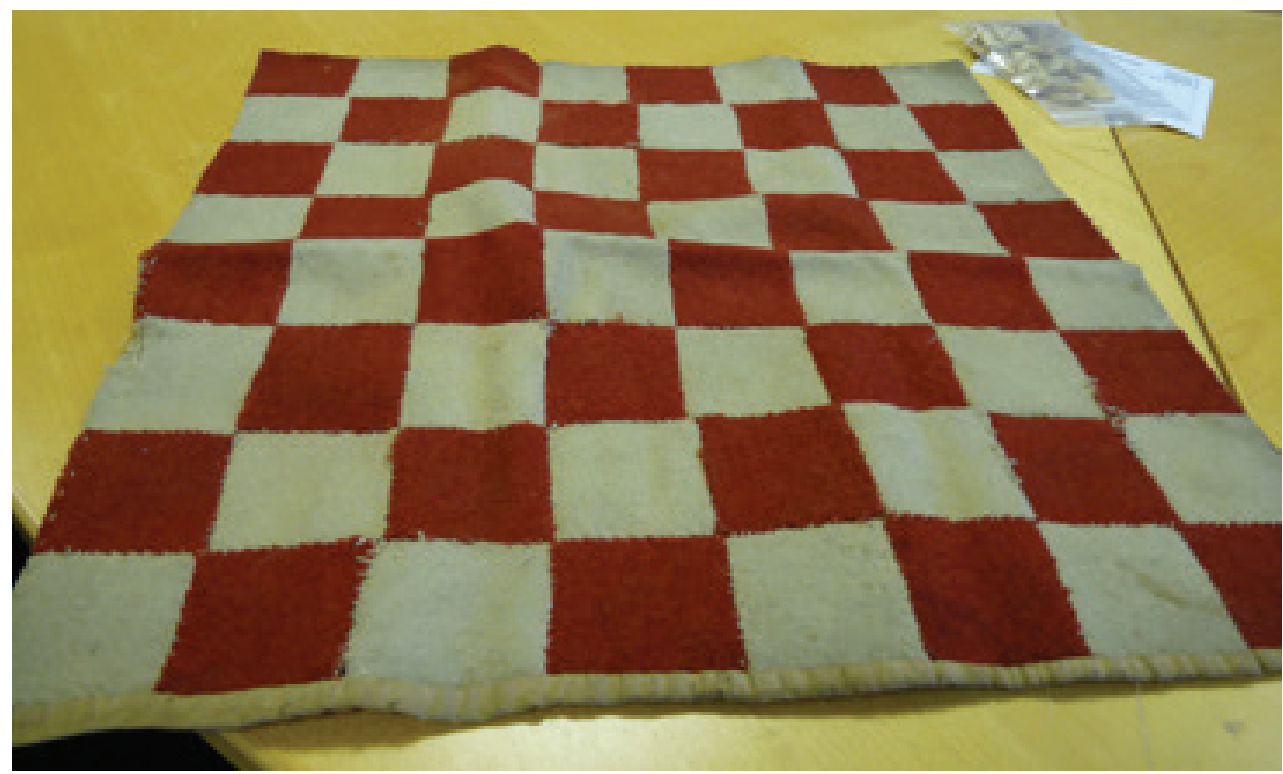

Fig 4. Drafts Board (NAM 1972-06-41-1) Reproduced with permission from the National Army Museum

Also in the collection is a Crimean War patchwork draft board, cannily produced so that the backing doubles as a bag in which to keep the pieces (which remain almost complete, with only one counter lost over the estimated 160 years since the object was made). Ties allow for easy rolling and compact portability. The Museum's catalogue provides the following detailed description:

Game of drafts, 1854 (c).

Board made from the uniforms worn by British soldiers and the pieces, twelve disks and eleven rectangles incised on top with a worm, made from bone. Reputedly made by soldiers during the Crimean War (1854-1856).Patchwork of 64 scarlet and white serge squares makes the board which is backed with white cotton and has a second backing sewn on to form a bag. (NAM,1972-06-41-1)

This object's biography made it particularly resonant to us, both as a memorial, providing an afterlife for the no-longer needed uniforms, and as a lively object of camaraderie, pass-timing, and likely gambling. Letters home from British soldiers in the Crimea often include accounts of pleasurable games of drafts and chess, although the correspondents are usually at pains to reassure their families that no gambling was involved. Like many pieces of soldier art, the 
board raises questions about the connections between battlefront and home, military and civilian life, destabilizing any firm separation of these spheres. It is homely, allowing men on campaign to continue a typical family game they had likely played at home and learnt as children from parents or older siblings. At the same time the board is an intensely military product, made from the material to hand and likely as a response to the long periods of empty time, particularly during the siege of Sebastopol, which made gambling such an absorbing occupation.

We had the privilege of interacting closely with this item at the NAM stores. Perhaps because of the layering of tactility in its history, as a handcrafted object then much handled (as the wearing on the counters attests) in playing, the board was the object we were most drawn to touch; we had the pleasure of revivifying it in an impromptu drafts game that attempted to recall its use by soldiers. In exhibiting soldier art curators might think about ways in which to recognize and meet, as far as is possible while prioritizing preservation, the tactile pull of these objects. ${ }^{9}$

We were also drawn to the board through the accompanying object narrative supplied by the museum catalogue. The description 'made from the uniforms worn by British soldiers' adds an additional layer of tactile history, as the material moves from intimate proximity to soldiers' bodies, to maker's or makers' hands, to players' hands, to ours. The identification of the material as from worn, used uniforms, suggests that it became surplus and available for reuse on the death of the wearers. This connects the board with powerful narratives circulated about military quilts as produced from the uniforms of dead fellow soldiers. In the letter, with which this article opened, Joseph Rawdon directly attaches this provenance to 'more than a few pieces' he used for his quilt, which also acts as memorial for the men who had previously worn material within it. In the quilts made in India that survive from this period, however, there was no evidence of the residue of use - oil, powder, blood - and it is more likely that the majority of materials came in the form of offcuts from regimental tailors. ${ }^{10}$ The curators of 'Homefront \& Battlefield: Quilts \& Context in the Civil War' found similarly, that sections within quilts reputed to be made from uniforms had pieces that were actually too large to come from unpicked jackets (Shaw and Bassett 2012: 121). ${ }^{11}$ The number of colours, taken from the relatively small fabric area of uniform facings, used in many military quilts (NAM's Leicestershire regiment coverlet, for example, incorporates large amounts of material from six colours), also make it unlikely that large, multi-colour patchworks were predominantly produced by uniforms of the dead, although it is possible that some parts of the material were made available in this way. The regularity, however, with which this kind of story is attached to these objects, shows the possible patriotic impulse for intimacy - proximity to the bodies of the heroic dead - and a desire for a rich narrative of the soldier maker's feeling, as the tactile experience of the detailed work of cutting, piecing and stitching combines with the emotional project of memorializing dead comrades. As commentators on the materiality of mourning have noted, clothing of the dead often has a particular resonance for the living providing a sense of direct physical connection. As Margaret Gibson puts it, "clothing engages a range of sensory memorial experiences linking the body of the bereaved to the body traces of the deceased' (2008: 118). ${ }^{12}$ The claimed inclusion of the uniforms of the dead, then, emphasizes the memorial function of military patchwork and the emotional labour of production. Another typical narrative, that the quilt has been produced by a wounded soldier, again takes its force from the object's direct connection to the suffering body but this time to that of the heroic survivor maker. In these cases, the patchwork is also linked to a reassuring narrative of recuperation, as the uniforms of the dead and suffering are remade into a form that can offer forms of physical and emotional comfort.

A similarly emotive object history is attached to an intricate Crimean war tablecloth in NAM's holdings:

Patchwork tablecloth, 1854-56 (c).

Scarlet, black, blue, yellow and white patches, reputedly cut from uniforms and made during the Crimean War (1854-1856) by drummer boys; backing of unbleached linen. 
Centrally, a white, 8 armed patch with white stars, beaded flowers and quatrefoils all round; a similar pattern is reproduced on all the surrounding squares.

All round is a scarlet border with zig-zag edge perforated with a continuous row of holes (NAM 1960-03-76-1).

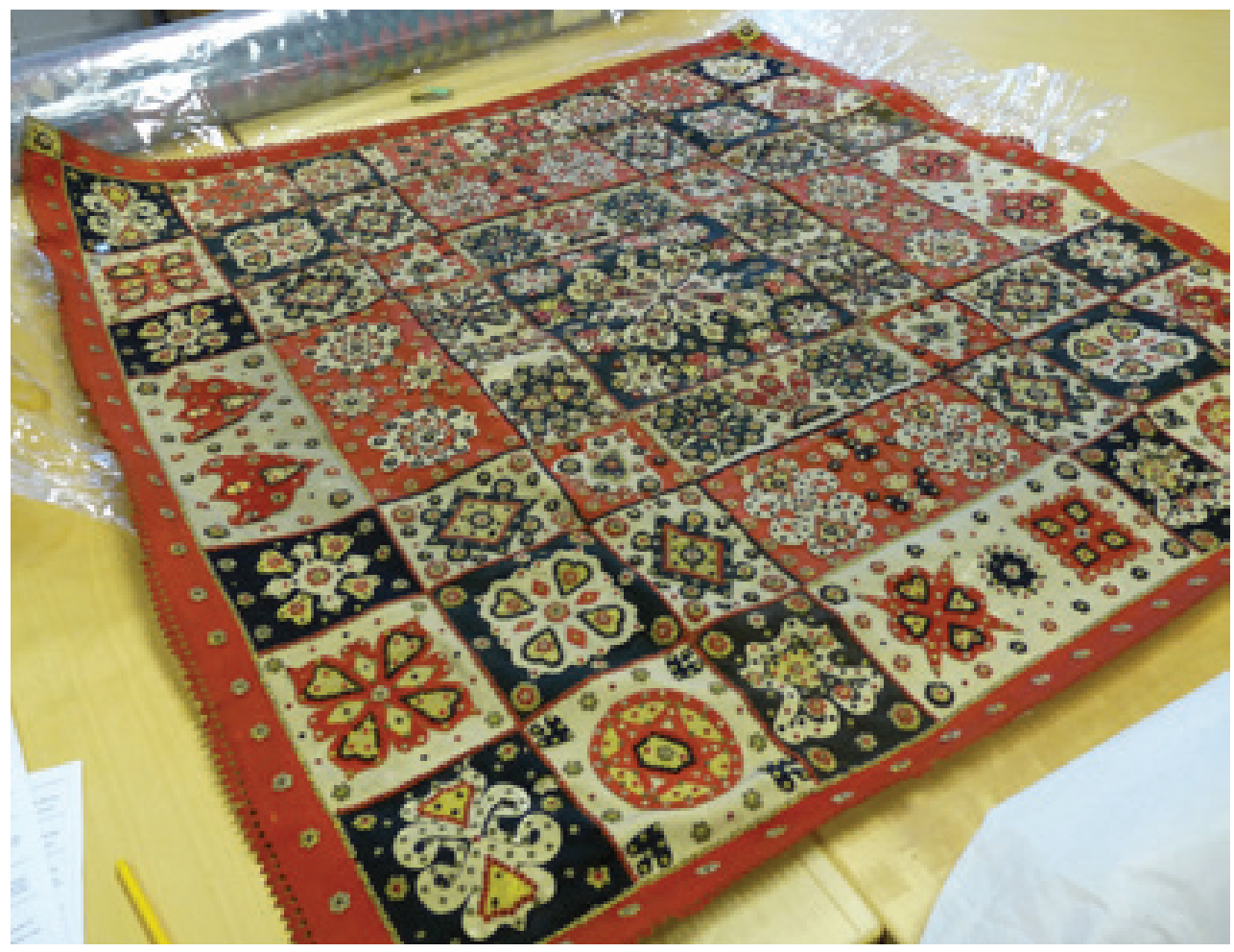

Fig 5. Patchwork Tablecloth (NAM 1960-03-76-1) Reproduced with permission from the National Army Museum

This beautiful, finely detailed object exhibits skilled piecing of layered small parts that produce an appearance of beading, and techniques of precise leather stamping that required specialist tools. The level of skill involved here differentiates it from many of the other soldier produced patchworks we've looked at. The drafts board and several of the NAM patchwork pieces rely on basic utility stitches, such as plain, back, and whip stitch, and the canvas-work embroidery of the slightly difficult to identify Leicester Tiger in the centre of the 17th Regiment coverlet is clearly the work of an amateur. The technical accomplishment, use of specialist equipment, and reliance on tiny pieces of thick cloth which act as beads and would be very difficult to keep hold of in camp conditions, makes it very unlikely that this was produced by drummer boys. Nonetheless the description gives this aesthetically striking object a similarly impressive sentimental biography. Drummer boys had wide popular appeal as figures of sympathy, and were often used in the nineteenth century in critiques of the waste and senselessness of war, as most famously, in Hardy's Boer war poem 'Drummer Hodge' (1899). In the Crimean War Punch featured a brave little drummer boy in a critique of officers who abused their position to leave the front 'on urgent private affairs' (24 November 1855: 209). This attribution also continues the association of military patchwork with the regular soldier. While officers had readier access to watercolours, oils, and drawing materials, and had often received formal 
artistic training through a private education, soldiers of other ranks had to be more adaptive in the materials and skills they brought to art work. Patchwork produced by drummer boys, privates, colour sergeants (a non-commissioned officer rank), reflect some unexpected tactile and aesthetic experiences of the working-class Victorian soldier.

The narratives attached to military patchworks provide insights into the ways in which soldier art is valued, variously by its producers, by the museums that preserve it, and by those viewing it now. Some feeling of proximity to the emotional life of the maker and/or the material is typically established by the catalogue description, which tends to ascribe at least the outline of a life story to at least one of these constituent parts (producer or fabric).

\section{Fit for a Queen: Private Thomas Walker's Patchwork}

The patchwork done by Private Thomas Walker as he convalesced from a head wound in the Fort Pitt military hospital at Chatham, made for a particularly detailed narrative relationship between soldier maker and patchwork, which widely circulated in the contemporary press. The details known about Walker perhaps suggest a fuller accompanying narrative for the anonymous Leicestershire Regiment coverlet also supposed to have been made by a convalescent soldier recovering from Crimean War wounds. Walker, of the 95th Regiment, was severely injured at the battle of Inkerman. He met the Queen during a series of Royal visits to the wounded, and she described him in her journal as

a most extraordinary case, a shell having burst on his head, the whole upper part of which was exfoliating, \& would come away! Yet he looked well in the face, \& said he did not suffer, only at times from giddiness. The Dr says he will entirely recover. ${ }^{13}$

The Times identified Walker as 'perhaps the most extraordinary case' among the wounded soldiers visited by the Queen: he 'has been in hospital nearly 12 months, during which time he had 13 pieces of his skull removed by Doctor Parry [. . . ] Her Majesty has seen him on every occasion of her visits, and has sent him a present of 10l' (17 April 1856: 12).

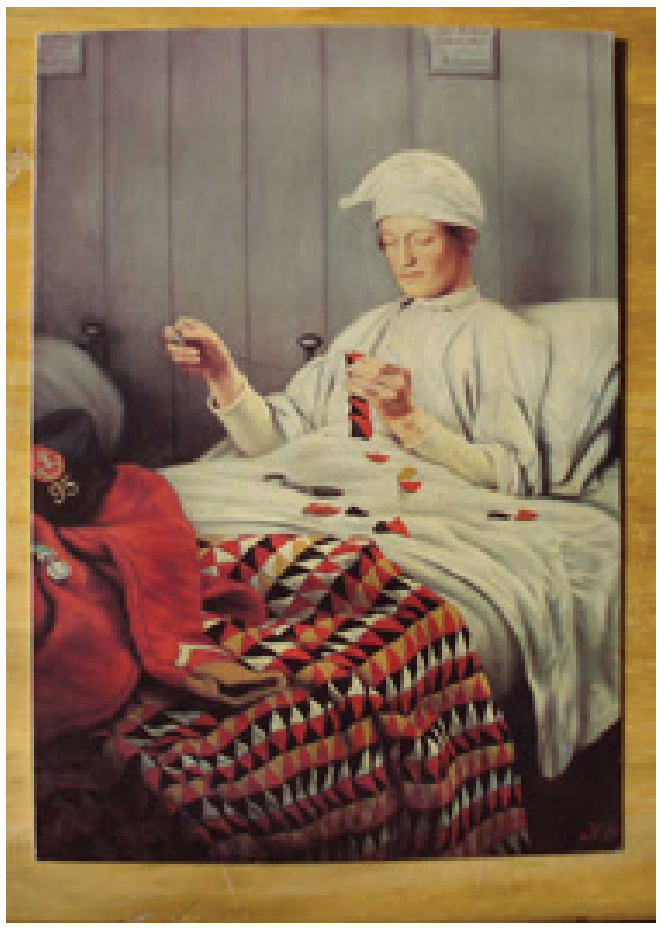

An 1856 portrait by Thomas Wood, now in the collection of the Royal College of Surgeons, depicts Walker propped up in bed making a vibrantly coloured quilt using the red, black, white and gold of army uniforms. Cassell's Illustrated Family Paper produced an engraving of Wood's painting, with which they included some details of how Walker had learnt to quilt in hospital with help from a fellow soldier's wife. As Glenn Fisher's research (2008) has shown, Walker's father was a brewer's servant and his own trade or calling was recorded on his attestation papers when he joined the 95th in 1850 as 'a hawker'. These papers also show that he was able to sign his own name. ${ }^{14}$ Although Walker seems to have learnt patchwork in hospital, the report in Cassell's suggests that he drew on his existing skills in hawking goods, to turn his sickbed work into a successful commercial enterprise:

Fig 6. Thomas William Wood, Portrait of Private Thomas Walker, 1856 Reproduced with permission from the Hunterian Museum at the Royal College of Surgeons 
He has employed much of his time in hospital, and relieved the tedium of hisconfinement, in making patchwork rugs and table covers from the scarlet clothand facings of soldiers' jackets. In the manufacture of these he has exhibited somuch taste and ingenuity that her majesty was pleased to select one for which she generously sent him $£ 10$; another large one has also been purchased from him, and he is now engaged in the making of a third, and still more handsome large rug, which he hopes to be able to dispose of to some charitably inclined persons. It deserves to be recorded to Walker's credit that he has given six pounds of her Majesty's donation to his relatives, who are in distressed circumstances, and £1 to the wife of a fellow patient who has assisted him in his work (5 July 1856).

Although, sadly, the Queen's Walker quilt does not survive as part of the Royal Collection, the archive at Windsor does demonstrate that the Queen continued to be interested in Walker's work and wellbeing. Following the Queen's Chatham hospital visits, an update on Walker's condition was sent to Colonel Phipps, keeper of the Privy Purse, who advised the Queen on her engagement with the war:

About ten days ago Dr Parry extracted a large piece of his skull very skillfully. He is going on very well \& amuses himself by making a patch work quilt of bits of cloth from soldiers coats, trousers and facings. He has shown great ingenuity in the devices he has chosen \& does it very nicely. ${ }^{15}$

Colonel Eden's commendation of Walker's 'ingenuity' of design, and nicety of work, is echoed by Cassell's report of Walker's 'taste and ingenuity' and his continuing endeavour to produce 'still more handsome' items, and by the emphasis in Wood's painting on the neatness and delicacy of execution, as Walker carefully stitches together small triangles of material to produce perfectly interlocking parti-coloured lines. This celebration of Walker's dextrous needlework and aesthetic skill gives a new dimension to the more conventional soldierly heroics signaled by his battle-wound. At the same time, these accounts work to reassure non-combatants about the rehabilitation of the wounded soldier, quickly returned to productivity and industry. Cassell's detailing of the monies Walker received and passed on for his work brings his narrative into the wider story of self-help and improvement promoted by the journal. Founder John Cassell welcomed content 'illustrative of the triumph of religion, temperance, morality, industry, energy and self-control over idleness, apathy, intemperance and habitual self-indulgence' (Nowell-Smith 1958: 42). In presenting Walker as a case-study of soldierly excellence, the journal overlapped with temperance organizations and army industrial exhibitions in commending craft-work over less productive pastimes. The curation of Wood's painting in the V\&A Quilts show drew out another strand of reassurance, contextualizing it as a 'propaganda portrait designed to allay public concerns over hospital conditions for soldiers.'

\section{The (dis)comfort of Salvage Work}

Wood's painting of Walker concentrated on his patchwork offers a variety of forms of comfort. This is an image of exemplary hospital hygiene and surgical skill; snowy white linens suggest an improbably high standard of ward cleanliness, and the head wound, recorded on the card above Walker's bed, has been treated through the dexterity of Staff Surgeon Parry (an interpretation of the painting emphasized through its presentation to the Royal College of Surgeons by the artist's nephew). Walker's own skilled production shows the wounded soldier swiftly rehabilitated into useful work. In producing a coverlet, which acts as a blanket over his feet during production, the patient is shown as useful to himself and other invalids, making one of the many necessaries which mismanagement of the war had rendered scarce. As a depiction of useful craftwork, this anticipates the specialized production of care equipment, such as splints, bandages and even artificial limbs, by convalescent soldiers during the First World War (Reznick 2004: 126). Beyond the practical implications, the image also offers a transformation of the violence of war apparent in Walker's head wound, as the trappings of militarism in the bold colours of the uniform are literally fragmented and remade into a form that gives comfort. The threat of the uniform is undone as it becomes a blanket to warm and cheer the convalescent soldier. This transformation is paralleled by the soldier's own activity, 
exchanging gun and bayonet for needle and thread. Yet, as well as the various reassurances offered by this image of the turning of uniforms into objects of comfort, and the transformation of the invalid into supposedly contented, productive worker, there is also an uneasiness, typically produced by the reclaiming of war materials in trench art. ${ }^{16}$ The inscrutability of Private Walker's expression in Wood's painting perhaps registers an ambivalence about soldiers' feelings towards such work. Though the Queen recites the reassurance he 'said he did not suffer' in her journal, and Cassell's reports that Walker had borne much suffering 'with cheerful resignation', the expression Wood gives Walker is certainly not cheerful. By making Walker's face unreadable Wood keeps Walker's feelings about his position and his 'therapeutic' work, a mystery, opening a space for doubt in the viewer's interpretation of the painting. This indeterminacy might also encourage attention to the other troubling elements of this image. The positioning of the scissors in Walker's lap, with their point directed to the centre of his crotch, uncomfortably suggests emasculation, even castration, by invalidism, and the craft work of the sickbed. This pointed reminder of the wounds suffered by Walker is extended by the surplus of available 'scrap' uniforms, in which we can perhaps glimpse the life and death narratives of those soldiers killed by the conflict that Walker narrowly survived.
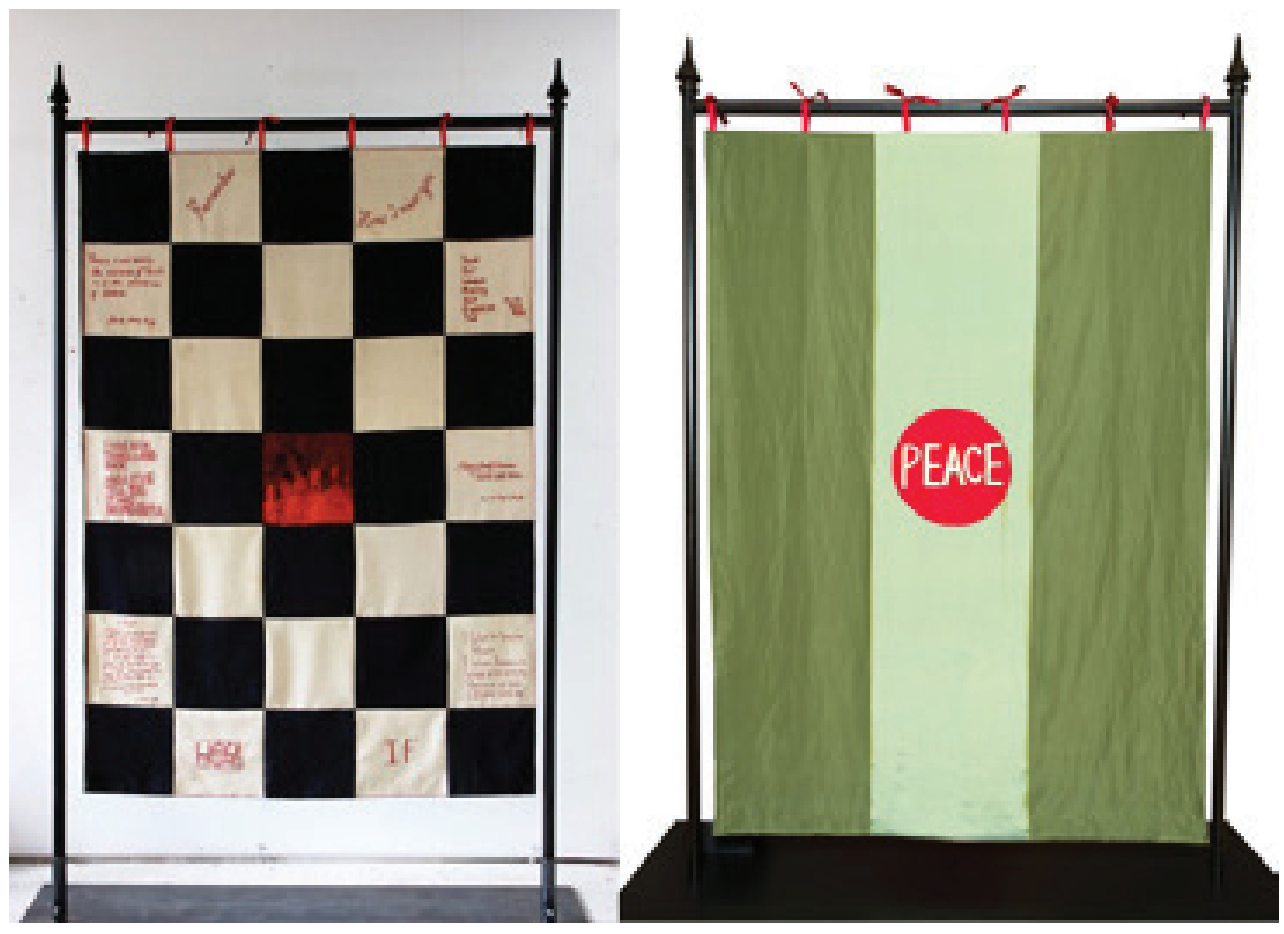

Fig 7. Susan Stockwell, Peace Maker (NAM 2014-05-1) Reproduced with permission from the National Army Museum

Contemporary artist Susan Stockwell recently produced a form of military quilt as part of NAM's 'Piece Makers' project with soldiers in rehabilitation and support centres. Stockwell used the patchwork form to combine hopeful narratives of recovery with the often painful, unsettled stories of veterans' experiences. Her work 'Peace Maker' (2014) incorporates panels of art produced by the soldiers she worked with, including a striking centrepiece by veteran Michael Crossan. The double-sided design refers to the textile culture of regiments in their banners and flags. On one face is a silken peace banner, while the other side is a checker-board design inspired by historical soldier-produced objects in the NAM collection, such as the Crimean War patchwork drafts board. This side is composed primarily of used army blankets in buff and 
dark grey, which bear faint stains of the lives of the servicemen and women who have touched them. ${ }^{17}$ This choice of used, stained, materials connects this modern quilt to the long history of military patchwork discussed here, in which objects often take their force from their direct contact with the bodies of soldiers. Stockwell's 'Peace Maker' literalizes the sense, powerful in work on materiality and mourning, of textiles as resonant with traces of former use. As Stockwell described it, the quilt provided a 'good metaphor to hang a range of ideas on'; her work being both recuperative, 'stitching people's lives back together', and a recognition of 'different lives' that can't always be reconciled. ${ }^{18}$ In the juxtaposition of the textures of the quilt's two sides, the smooth silk, and the rough blankets, the piece resonates with the contradictions typically inherent in trench art, as material that can simultaneously celebrate, commemorate, and criticize war. Stockwell's selection of patchwork shows the continuing resonance of this form for soldiers and civilians. Curating the textile histories of soldier art clearly makes for powerful visitor engagement, allowing us to feel at the same time better and worse about war and to question entrenched attitudes about masculinity, soldiering, and militarism.

Received: 15 June 2014

Finally accepted:30 June 2015

\section{Notes}

1 We are grateful to Pip Dodd and Alastair Massie of the National Army Museum for enabling our work with the substantial military patchwork holdings there.

2 These objects might usefully be considered alongside contemporary textile based objects which document violence or suffering, for example the appliqued arpilleras which were recently included in the V\&A's 'Disobedient Objects' exhibition ( 26 July 2014 - 1 February 2015). Although once classified as folk art, arpilleras, produced by women in Chile under General Pinochet's dictatorship, these pictorial hangings have been reclaimed as symbols of protest and solidarity against military atrocities. See Flood and Grindon 2014: 122-123. This pictorial element of the arpilleras, in which women narrate their experience of war and conflict is shared by the Afghan rug weavers, who since 1979 have featured images of the Soviet invasion of and withdrawal from Afghanistan, tanks, hand grenades and, more controversially, the destruction of the World Trade Centre on 9.11.

3 On the latter category see Greenblatt, 1990. Maines and Glynn discuss the psychological significance of particular artefacts that seem 'as if they are, to use a term from Roman paganism, inhabited by a numen or spirit that calls forth in many of us a reaction of awe and reverence' (1993: 9).

4 Gregson and Crew use the term 'commodity biographies' in their work on how the value of certain second hand objects, especially clothing, is determined by the imprint of previous use upon it. In a formulation which has been helpful to our thinking about military patchwork, they define commodity biography as 'the full range of biographical transformations which commodities undertake [. . .] What are the significant moments in a commodity's life?' (2003: 170)

5 The conference was jointly convened by the Danish National Research Foundation's Centre for Textile Research, the University of Copenhagen and the Royal Danish Defence College (Copenhagen, 20-21 May 2008). Textile History is the journal of The Pasold Research Fund.

6 For discussions of plunder, and the blurred line between souvenir and trophy hunting, see Harrison (2012) and Furneaux (2016: chapter 5).

7 See Smith 2008.

8 'Observations upon War Office Scheme for the Employment and Tuition of Soldiers and their Children in Trades and Calling.' 2 Jan 1862, SWO/202, 45-47. 
9 This is a perennially tricky question for curators. The V\&A Quilts exhibition did not have a handling collection due to concerns about sending out mixed messages: don't touch here, but do here. One possibility for allowing more hands-on experience would be to recreate similar objects, possibly via workshops with a soldiers' rehabilitation charity.

10 For a more detailed discussion of the mythology of military quilt materials see Prichard 2010.

11 Shaw and Bassett also explore the valuing of textile fragments that had 'touched the tragedy of the war' (2012: 186), including uniforms worn by casualties and survivors, as a form of memorial.

12 For further consideration of relic objects, often including clothing or body pars such as hair see Hallam and Hockey 2001: 164-5.

13 Queen Victoria's Journal, The Royal Archives, 19 June 1855, Vol 39, 343.

14 Walker made an apparently full recovery, working as a labourer in Buckinghamshire, marrying, and having one son. He died in 1889 aged 62.

15 Colonel Eden to Colonel Phipps, 4 November 1855. Royal Archives VIC/MAIN/F/3/115

16 Saunders has considered the uncomfortable mixed meanings that compete in WW1 shell case art, seeing these objects as 'redolent with irony'. Ambiguities of meaning are produced by differences between military use and the often pastoral design of shell case vases, and the transitions of use. Expended shells were struck as gas alarms and then, after the war, reused as domestic dinner gongs (2003: 72 and chapter 5).

17 This continues Stockwell's practice of stitching together commonplace objects which contain 'stains of existence', such as used paper bank notes which have passed through many hands. In 'A Chinese Dream' (2010), specially commissioned for the V\&A Quilts exhibition she machined stitched together new and used Chinese bank notes of various denominations to form a visually arresting map of the world, which reflects on the strength and influence of China's global relevance, particularly to the textile trade.

18 Susan Stockwell, film for the 'Piece Makers' exhibition, NAM, 2014.

\section{References}

Aggett, W.J.P. (1994) The Bloody Eleventh: History of The Devonshire Regiment, Vol II 1815-1914, Exeter: The Regiment.

Anon. 'The New Game of Follow My Leader', Punch, 24 November 1855, no. 750, vol. 29.

Anon. 'Visit Of Her Majesty To The Military Hospitals At Chatham', The Times, 17 April 1856.

Classen, C. (2005) The Book of Touch, London, Berg.

Fisher, G. (2008) 'Thomas Walker 95 $5^{\text {th }}$ Regiment', The War Correspondent, Journal of the Crimean War Research Society, 26.3, 23-24.

Flood, C. and Grindon, G. (eds) (2014) Disobedient Objects, London.

Furneaux, H. (2016, forthcoming) Military Men of Feeling: Emotion, Touch and Masculinity in the Crimean War, Oxford: Oxford University Press. 
Gibson, M. (2008) Objects Of The Dead: Mourning And Memory In Everyday Life, Melbourne: Melbourne UP.

Greenblatt, S. (1990) 'Resonance and Wonder', Bulletin of the American Academy of Arts and Sciences 43.4, 11-34.

Gregson, N. and Crew, L. (2003) Second Hand Cultures, Oxford and New York: Berg.

Hallam, E. and Hockey, J. (2001) Death, Memory and Material Culture, Oxford: Berg.

Harrison, S. (2012) Dark Trophies: Hunting and the Enemy Body in Modern War, New York and Oxford: Berghahn.

Hensher, P. (9 May 2010) The Mail on Sunday.

Jacob, M. J. (2007) 'Material with a Memory', in The Object of Labour: Art, Cloth and Cultural Production, Chicago, MIT.

Kimball, J. (2004) Trench Art: An Illustrated History, Davis, CA: Silverpenny Press.

Maines, R. and Glynn, J. (1993) 'Numinous Objects', The Public Historian, 15.1, 8-25.

Nosch, M. (2010) 'Textile History and the Military', Textile History, 41 supplement 1, 1-5.

Nowell-Smith, S. (1958) The House of Cassell 1848-1958, London: Cassell \& Co.

Parker, R. (1984, reissued 2010) The Subversive Stitch: Embroidery and the Making of the Feminine, London, I.B. Tauris.

Prichard, S. (2010) 'Precision Patchwork: Nineteenth Century Military Quilts', Textile History, 41 supplement 1, 214-226.

Rae J. and Tucker M. (eds) (1995) Quilters' Guild Heritage Collection: Quilt Treasures of Great Britain, London: The Quilters' Guild.

Reznick, J. (2004) Healing the Nation: Soldiers and the Culture of Caregiving in Britain During the Great War, Manchester: Manchester UP.

Rose, C. (2009), Exhibition Knowledge: British Inlaid Patchwork in Inlaid Patchwork in Europe from 1500 to the Present, Berlin, Museum Europäischer Kulturen, 87-98.

Saunders, N. (2002) Trench Art, Buckinghamshire: Shire (2003) Trench Art: Materialities and Memories of War, Oxford: Berg

Shaw, M. and Bassett, L. Z. (2012), Homefront and Battlefield: Quilts and Context in the American Civil War, Lowell MA: American Textile History Museum.

Smith, C. (2008) 'Doing Time: Patchwork as a tool of social rehabilitation in British Prisons', V\&A Online Journal, Issue 1. 
${ }^{*}$ Holly Furneaux is Professor in English at Cardiff University. She is author of Queer Dickens: Erotic, Families, Masculinities (Oxford University Press, 2009). She is also co-editor, with Sally Ledger, of Dickens in Context (Cambridge University Press, 2011) and editor of John Forster's Life of Dickens (Sterling, 2011). Her next book, Military Men of Feeling: Emotion, Touch and Masculinity in the Crimean War (Oxford University Press) will be out in spring 2016.

Professor Holly Furneaux

School of English, Communication and Philosophy

Cardiff University

John Percival Building

Colum Drive

Cardiff CF10 3EU

Email: FurneauxH@Cardiff.ac.uk

Ysgol Saesneg, Cyfathrebu ac Athroniaeth Caerdydd

Prifysgol Caerdydd

Adeilad John Percival

Colum Drive

Caerdydd

CF10 3EU

Ebost: FurneauxH@caerdydd.ac.uk

** Sue Prichard is Senior Curator of Decorative Arts at Royal Museums Greenwich. She worked at the V\&A for fourteen years, specialising in modern and contemporary textiles. She was lead curator for the major exhibition 'Quilts 1700-2010', and curated a series of displays focusing on the V\&A's extensive textile collection. She has published and lectured both nationally and internationally. Her research interests are domesticity and the handmade, soldiers' craft, folk art and British art and design 1930-1960.

Sue Prichard

Senior Curator Decorative Arts

Royal Museums Greenwich

Greenwich

London SE10 9NF

sprichard@rmg.co.uk 